\title{
Temperature Stress of Roller Compacted Concrete Base of Durable Asphalt Pavement
}

\author{
Li Shanqiang ${ }^{1, ~ a ~, ~ L i ~ H a o ~}{ }^{2, b}$, Zhou Yong ${ }^{3, \mathrm{c}}$ and Zhang Guomin ${ }^{3, \mathrm{~d}}$ \\ ${ }^{1}$ School of Road, Chang'an University, Xi'an 710064, Shanxi, China \\ ${ }^{2}$ Research and Development Center on Road Transport Safety and Emergency Support \\ Technology \& Equipment, Ministry of Transport, PRC, Guangzhou 510420, Guangdong, China; \\ ${ }^{3}$ Guangdong Hualu Communications Technology Co.LTD, Guangzhou 510420, Guangdong, \\ China

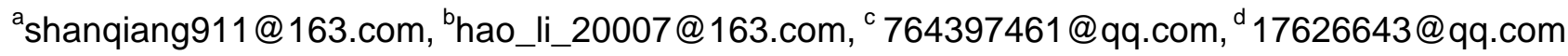

Keywords: Asphalt pavement; Roller compacted concrete; Temperature stress; Temperature shrinkage performance; Finite element method.

Abstract. Earlier research has demonstrated that rigid base, when properly applied, can enhance the cracking and rutting resistance of asphalt concrete layers in pavements. This study focussed on developing the temperature stress distribution of roller compacted concrete(RCC) base by conducting appropriate experiments and developing a simplified theoretical model in the case of the transient loading situation.To demonstrate the effect of the length, width, thickness of roller compacted concrete plate, temperature shrinkage coefficient, modulus, temperature gradient and the thickness of asphalt layer, a series of three-dimensional finite element simulations were conducted.To demonstrate the temperature shrinkage performance of RCC, a large number of laboratory tests were conducted.

The results indicated that changing the variables of RCC influenced the temperature stress distribution in laboratory specimens. Increasing the width, thickness of roller compacted concrete plate and decreasing the other factors can assited in reducing the temperature stress. In addition, laboratory tests showed that compared with the traditional semi-rigid base, the temperature shrinkage coefficient of RCC is less, the cracking resistance of RCC is better, and the decrease amplitude of temperature stress is $40 \%$. It can realize the durability of RCC base of asphalt pavement by reasonable construction technology and structure design.

\section{Introduction}

Roller Compacted Concrete (RCC) is a kind of dry concrete with less water, zero slump ultra, which is suitable for mass concrete engineering ${ }^{[1-4]}$. Compared with traditional semi-rigid base asphalt pavement, the strength and fatigue resistance of the RCC base asphalt pavement is more excellent, the deflection of surface is smaller, which can prevent fatigue damage and structural rutting, the temperature stress can be released by using precut joints, and the ability of anti erosion is better ${ }^{[5-7]}$. The pavement has a certain economic advantage in the material and structure, and it is used to solve the problem of the durability of asphalt pavement in Guangdong area, which is based on the large number of early damages of asphalt pavement in Guangdong area. Therefore, according to the special climatic condition of Guangdong region,this article used the ANSYS finite element software to study temperature stress of RCC base asphalt pavement, which can provide certain reference for the road structure design.

\section{Calculation model and parameter selection}

In this paper, the three-dimensional finite element model of temperature stress analysis is used, calculation assumptions are that the elastic body of each layer is homogeneous, continuous and isotropic, the interlayer connection is smooth; the base is fixed on the bottom side of the foundation, the normal displacement has constraints; the asphalt layer above the foundation has the free boundary; 
the asphalt concrete plate is continuous and seamless; the width of cutting seam of roller compacted concrete is $1 \mathrm{~cm}$, the cutting seam has no ability to transfer pressure.

The length of the model is $8 \mathrm{~m}$, the width of the model is $4 \mathrm{~m}$, the width of cutting seam is $1 \mathrm{~cm}$, the length and width of the foundation is the same as that of roller compacted concrete. The basic size of the foundation is to simulate the characteristics of semi infinite space, expanding the basic length to $10 \mathrm{~m}$, width to $6 \mathrm{~m}$, high to $6 \mathrm{~m}$; using SOLID5 unit, then dividing the grid as shown in Fig.1. The thermal conductivity of roller compacted concrete is $1.5 \mathrm{w} / \mathrm{m}^{\circ} \mathrm{C}$, and the linear expansion coefficient is $1.0 \times 10^{-5}\left(1 /{ }^{\circ} \mathrm{C}\right)$.

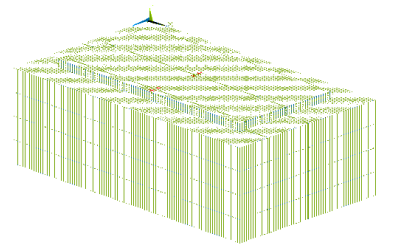

Fig. 1 Three-dimensional finite element model of pavement structure Table 1 Parameters of asphalt pavement structure layer of roller compacted concrete

\begin{tabular}{cccccc}
\hline Structure layer type & $\begin{array}{c}\text { Modulus of } \\
\text { elasticity } \\
(\mathrm{MPa})\end{array}$ & $\begin{array}{c}\text { Structure } \\
\text { layer } \\
\text { thickness } \\
(\mathrm{cm})\end{array}$ & $\begin{array}{c}\text { Poisson's } \\
\text { ratio }\end{array}$ & $\begin{array}{c}\text { Thermal } \\
\text { conductivity }( \\
\left.\mathrm{w} / \mathrm{m}^{\circ} \mathrm{C}\right)\end{array}$ & $\begin{array}{c}\text { Temperature } \\
\text { shrinkage coefficient } \\
\left(1 /{ }^{\circ} \mathrm{C}\right)\end{array}$ \\
\hline Asphalt surface & 1400 & 10 & 0.25 & 1.2 & $2.1 \times 10^{-5}$ \\
Roller compacted concrete base & 23000 & 24 & 0.15 & 1.5 & $1.0 \times 10^{-5}$ \\
Semi rigid material & 2000 & 20 & 0.25 & 1.3 & $1.0 \times 10^{-5}$ \\
Foundation & 200 & - & 0.35 & 1 & $0.5 \times 10^{-5}$ \\
\hline
\end{tabular}

\section{Model verification}

Specification results.In the case of cement pavement design, the parameters of the cement concrete pavement are as follows: the temperature gradient is $53 / \mathrm{m}$; the thickness of the cement concrete pavement is 0.26 ; the length of the plate is $5 \mathrm{~m}$; the cement concrete modulus is $29 \mathrm{GPa}$; the thermal expansion coefficient is $1.0 \times 10^{-5} /{ }^{\circ} \mathrm{C}$, and the calculated stiffness radius is $0.916 \mathrm{~m}$.

The calculation process is as follows:

$$
\begin{aligned}
& t=\frac{L}{3 r}=\frac{5}{3 \times 0.916}=1.819 C_{L}=1-\frac{\sinh (1.819) \cos (1.819)+\cosh (1.819) \sin (1.819)}{\cos (1.819) \sin (1.819)+\sinh (1.819) \cosh (1.819)}=0.735 \\
& B_{L}=1.77 \times e^{-4.48 \times 0.26} \times 0.735-0.131 \times(1-0.735)=0.371
\end{aligned}
$$

The temperature stress of concrete slab is maximum when temperature gradient is maximum.

$$
\sigma_{t \max }=\frac{\alpha_{c} E_{c} h_{c} T_{g}}{2} B_{L}=\frac{10^{-5} \times 29000 \times 0.26 \times 53}{2} \times 0.371=0.741 \mathrm{MPa}
$$

Finite element simulation results.In the case of the same parameters, the critical load of the roller compacted concrete base plate and the top of the plate is calculated by using the same parameters as the cement pavement design specification, and the longitudinal stress contours of the roller compacted concrete base plate at the bottom and the top of the slab are shown in Fig.2.

As shown in Fig.2 and Fig.3, it can be seen that the top of the plate bears compression, stress reached the maximum in the middle of plate, and it does not matter whether it is close to the longitudinal seam or not; the bottom of the plate bears tensile stress, stress reached the maximum in the middle of plate too, and it does not matter whether it is close to the longitudinal seam or not. The finite element method for calculating the maximum temperature stress is $0.756 \mathrm{MPa}$ in the standard, and the calculated value by using the finite element method is $0.741 \mathrm{MPa}$. The deviation is $3 \%$, the results can be used for engineering applications. 


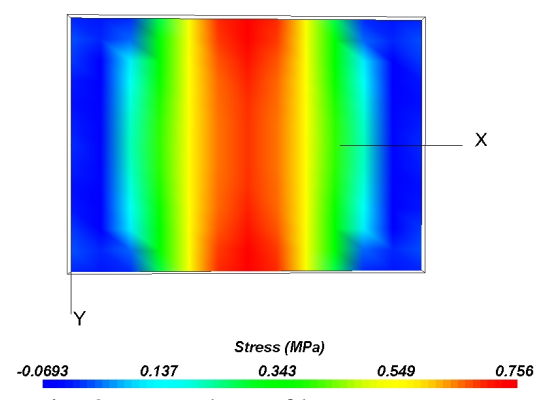

Fig. 2 stress chart of bottom temperature

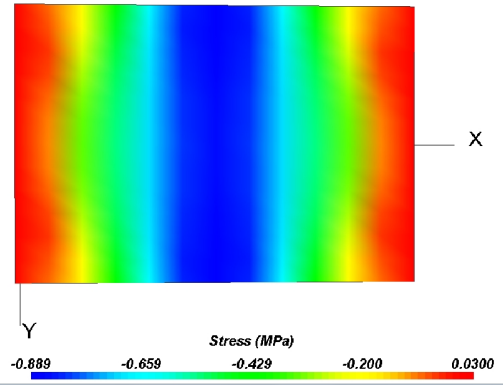

Fig. 3 stress chart of the top temperature of the plate

\section{The influence of different parameters on the temperature stress of roller compacted concrete}

In order to analyze the characteristics of pavement structure response under the influence of temperature load, changing one factor by fixing the other factors. The temperature of the top of plate is $20^{\circ} \mathrm{C}$, the temperature of the bottom of plate is $5^{\circ} \mathrm{C}$.

The length of RCC slab. Assuming that the length of RCC slab changes from $5 \mathrm{~m}$ to $20 \mathrm{~m}$, fixing other parameters meanwhile. The critical load of the bottom stress of RCC slab are shown in Table 2 . Table 2 The bottom stress of RCC slab when the length of RCC layer changed

\begin{tabular}{cccccccccc}
\hline Long board & 5 & 6 & 8 & 10 & 12 & 14 & 16 & 18 & 20 \\
\hline Tensile stress in bottom & 0.743 & 1.156 & 1.832 & 2.18 & 2.43 & 2.65 & 2.86 & 3.06 & 3.22 \\
\hline
\end{tabular}

From Table 2, it can be seen that, with the increase of RCC slab, the stress of the bottom of the RCC layer increases rapidly, but the amplitude decreases. The length changes from $5 \mathrm{~m}$ to $6 \mathrm{~m}$, the tensile stress in the bottom of the slab increased by $0.413 \mathrm{MPa}$, which increases by $50 \%$; the length changes from $14 \mathrm{~m}$ to $16 \mathrm{~m}$, the tensile stress in the bottom of the slab increased by $0.13 \mathrm{MPa}$, which increases by $8 \%$.

The width of RCC slab. Assuming that the width of RCC slab changes from $4 \mathrm{~m}$ to $14 \mathrm{~m}$, fixing other parameters meanwhile. The results are shown in Table 3.

Table 3 The bottom stress of RCC slab when the width of RCC layer changed

\begin{tabular}{ccccc}
\hline RCC Long board $(\mathrm{m})$ & 4 & 7 & 11 \\
\hline Tensile stress in bottom (MPa) & 1.817 & 1.67 & 1.523 & 1.376 \\
\hline
\end{tabular}

From Table 3, it can see that the plate is wider and the critical load is smaller. The width changes every 2 meters, the stress decreases about $0.12 \mathrm{MPa}$. When the width increases, it can disperse temperature stress at the critical position effectively. However, the changing amplitude of the temperature stress at the critical position caused by the change of the width is less than the length. When the foundation is not uniform, the increasing in width may cause adverse effects.

The thickness of RCC slab . Assuming that the thickness of RCC slab changes from $14 \mathrm{~cm}$ to $30 \mathrm{~cm}$, fixing other parameters meanwhile. The results are shown in Table 4.

Table 4 The bottom stress of RCC slab when the thickness of RCC layer changed

\begin{tabular}{cccccc}
\hline RCC layer thickness $(\mathrm{cm})$ & 14 & 18 & 22 & 26 & 30 \\
\hline Tensile stress in bottom $(\mathrm{MPa})$ & 1.961 & 1.605 & 1.064 & 0.743 & 0.552 \\
\hline
\end{tabular}

From Table 4, it can be seen that with the increase of the thickness of RCC layer, the temperature stress of RCC layer decreases, the thickness increases every $3 \mathrm{~cm}$, and the bottom tensile stress decreases by about $0.3 \mathrm{MPa}$. However, the increase of the thickness of roller compacted concrete will cause the difference of temperature, and the effect of increasing the thickness of RCC layer to decrease the temperature stress will be slightly reduced. Increasing the thickness can effectively spread the deformation caused by the change of temperature and reduce the stress of RCC.

The temperature shrinkage coefficient of RCC slab.Temperature shrinkage coefficient is a key performance parameter of $\mathrm{RCC}$, it has a great influence on the temperature stress of pavement structure. It is the direct cause of temperature stress. The temperature shrinkage coefficient is changing from $0.8 \times 10^{-5} /{ }^{\circ} \mathrm{C} \sim 1.3 \times 10^{-5} /{ }^{\circ} \mathrm{C}$, increasing every $0.1 \times 10^{-5} /{ }^{\circ} \mathrm{C}$, and The results are shown in Table 5 . 
Table 5 The bottom stress of RCC slab when the temperature shrinkage coefficient of RCC layer changed

\begin{tabular}{cccccccc}
\hline Temperature shrinkage coefficient $\left(10^{-5} /{ }^{\circ} \mathrm{C}\right)$ & 0.8 & 0.9 & 1 & 1.1 & 1.2 & 1.3 \\
\hline Tensile stress in bottom $(\mathrm{MPa})$ & 0.631 & 0.695 & 0.743 & 0.798 & 0.841 & 0.893 \\
\hline
\end{tabular}

From table 5, with the increase of temperature shrinkage coefficient, the temperature of RCC slab increases linearly. When the temperature shrinkage coefficient increases from $0.8 \times 10^{-5} /{ }^{\circ} \mathrm{C}$ to $0.9 \times$ $10^{-5} /{ }^{\circ} \mathrm{C}$, the bottom of the RCC layer increased by $0.064 \mathrm{MPa}$. The greater the temperature shrinkage coefficient is, the more sensitive it is to the change of temperature, so the temperature stress in the roller compacted concrete is greater.

The temperature gradient of RCC slab. Assuming that the temperature gradient of RCC slab changes from $10^{\circ} \mathrm{C}$ to $30^{\circ} \mathrm{C}$, fixing other parameters meanwhile. The results are shown in Table 6 . Table 6 The bottom stress of RCC slab when the temperature gradient of RCC layer changed

\begin{tabular}{cccccc}
\hline RCC temperature rise ${ }^{\circ} \mathrm{C}$ & 10 & 15 & 20 & 25 & 30 \\
\hline Layer bottom tensile stress $(\mathrm{MPa})$ & 0.163 & 0.418 & 0.743 & 1.049 & 1.239 \\
\hline
\end{tabular}

From Table 6, it can be seen that, with the increase of the temperature of the roller compacted concrete, the stress of the roller compacted concrete increases linearly. The tensile stress at the bottom of the slab is $0.163 \mathrm{Mpa}$ when temperature at the bottom of the slab is $5^{\circ} \mathrm{C}$ and temperature at the top is $10^{\circ} \mathrm{C}$, The tensile stress at the bottom of the slab is $1.239 \mathrm{MPa}$ when temperature at the bottom of the slab is $5^{\circ} \mathrm{C}$ and temperature at the top is $30^{\circ} \mathrm{C}$. The tensile stress of the roller compacted concrete slab increases $1.07 \mathrm{MPa}$.

The thickness of asphalt surface.Asphalt surface can improve the suitability and driving comfort of roller compacted concrete. The asphalt layer has a restriction on the warping deformation of roller compacted concrete slab. The other parameters are fixed, and the thickness of asphalt layer is changed from $0-0.25 \mathrm{~m}$, the results are shown in table 7.

Table 7 The bottom stress of RCC slab when the thickness of asphalt surface changed

\begin{tabular}{ccccccc}
\hline Asphalt layer thickness (cm) & 0 & 10 & 15 & 20 & 25 \\
\hline Layer bottom tensile stress (MPa) & 0.743 & 0.797 & 0.841 & 0.882 & 0.931 \\
\hline
\end{tabular}

From Table 7, the thickness of asphalt layer is $0 \mathrm{~m}$, the tensile stress is $0.743 \mathrm{MPa}$, the thickness of asphalt layer is $0.1 \mathrm{~m}$, and the tensile stress is $0.797 \mathrm{MPa}$. The thickness of asphalt layer increases, so does the stress of roller compacted concrete. Increasing the thickness of asphalt layer will cause the internal stress of roller compacted concrete increasing, and the thickness increases every $0.1 \mathrm{~m}$, the tensile stress increases $0.05 \mathrm{MPa}$. But if the temperature gradient is considered, the thickness of asphalt layer is favorable to reduce the temperature stress of roller compacted concrete.

The modulus of RCC slab.RCC layer modulus is an important parameter of material. The aggregate gradation is the same, the cement content increases, the roller compacted concrete modulus will be improved. The mechanical strength of roller compacted concrete will be improved, but the capacity of deformation coordination of the material will be weakened. Assuming that the modulus of RCC slab changes from $21000 \mathrm{Mpa}$ to $29000 \mathrm{Mpa}$, fixing other parameters meanwhile. The results are shown in Table 8.

Table 8 The bottom stress of RCC slab when the modulus of RCC slab changed

\begin{tabular}{cccccc}
\hline Roller compacted concrete base modulus (Mpa) & 21000 & 23000 & 25000 & 27000 & 29000 \\
\hline Layer bottom tensile stress (MPa) & 0.658 & 0.683 & 0.711 & 0.732 & 0.755 \\
\hline
\end{tabular}

From Table 8, it can be seen that with the increase of the modulus of roller compacted concrete, the stress of the roller compacted concrete increases linearly.

Results.Through analysing the changing rule of temperature stress of seven factors, the results show that the more the width, thickness of RCC plate is, the more temperature stress is, and vice versa. The rest five factors increases, the temperature stress decreases. But the plate width may cause adverse effects on the stress of the plate, and the thickness of asphalt layer is favorable to reduce the temperature stress of roller compacted concrete. 


\section{Experimental study on temperature shrinkage performance of RCC}

The volume deformation of roller compacted concrete material is greatly affected by temperature. The greater the temperature shrinkage coefficient is, the larger the volume deformation of the material is. Too large volume deformation can easily lead to the cracking of roller compacted concrete, increasing the amount of cutting seam expansion has a bad effect on the durability of asphalt pavement. Therefore, it is necessary to study the temperature shrinkage coefficient and the influence of the factors on the roller compacted concrete material. Using instrument method to study temperature shrinkage performance of roller compacted concrete.

Test plan.Considering cement dosage, water consumption, sand percentage (grading), aggregate type. Based on the reference mix ratio, changing cement dosage, water consumption, sand ratio, aggregate type in turn, the proportion of each component is shown in Table 9.

\begin{tabular}{|c|c|c|c|c|c|c|c|}
\hline $\begin{array}{c}\text { Material } \\
\text { specification }\end{array}$ & $10 \sim 20 \mathrm{~mm}$ & $5 \sim 10 \mathrm{~mm}$ & $0 \sim 5 \mathrm{~mm}$ & River sand & $\begin{array}{l}\text { Cement dosage } \\
(\mathrm{kg} / \mathrm{m} 3)\end{array}$ & $\begin{array}{l}\text { Water consumption } \\
\qquad(\mathrm{kg} / \mathrm{m} 3)\end{array}$ & Number \\
\hline \multirow{7}{*}{$\begin{array}{l}\text { Material } \\
\text { proportion } \\
(\%)\end{array}$} & 46 & 14 & 13 & 27 & 240 & 122 & $\mathrm{AZ}$ \\
\hline & 41 & 14 & 10 & 35 & 240 & 122 & BS1 \\
\hline & 45 & 15 & 23 & 17 & 240 & 122 & BS2 \\
\hline & 46 & 14 & 13 & 27 & 200 & 122 & $\mathrm{BC} 1$ \\
\hline & 46 & 14 & 13 & 27 & 280 & 122 & $\mathrm{BC} 2$ \\
\hline & 46 & 14 & 13 & 27 & 240 & 132 & BW1 \\
\hline & 46 & 14 & 13 & 27 & 240 & 112 & BW2 \\
\hline
\end{tabular}

Test method.After 90 days of curing, the specimen was pasted by a thin glass, which was placed in temperature-controlled box. Using paraffin wax and plastic film to seal the whole specimen, making thin glass sheets exposed. The specimens were placed into the contractile apparatus, then installing dial gauge, dial gauge meter should in the middle position of the thin glass, as shown in Fig.4.

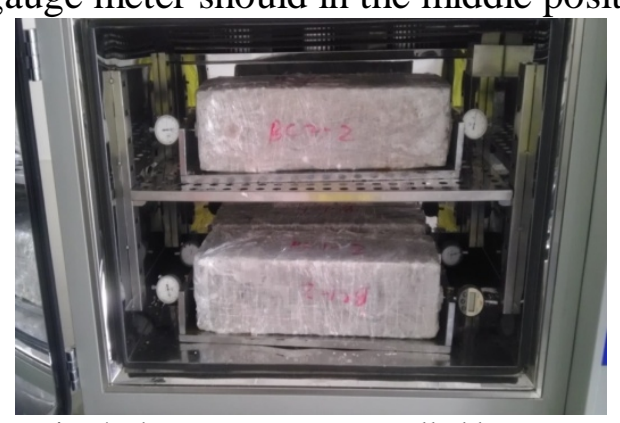

Fig. 4 The temperature-controlled box

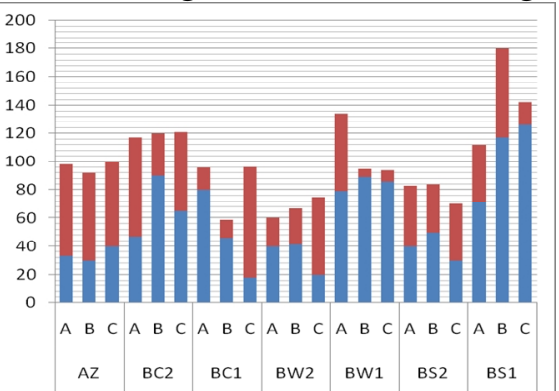

Fig. 5 Temperature shrinkage deformation

Setting the temperature of the controlled box to $-10^{\circ} \mathrm{C}$, after 4 hours in constant temperature, recording the dial gauge readings every 4 hours. The temperature increases $2{ }^{\circ} \mathrm{C}$ every time, when the temperature reached $0^{\circ} \mathrm{C}$, temperature increases $5{ }^{\circ} \mathrm{C}$ every 4 hours, it has been heated up to $40{ }^{\circ} \mathrm{C}$.

Test results.In Fig. 5, the front part of the number of specimen is material composition, number 1, 2, 3 (Table 9) or ABC (Fig.5) is the repeated specimen, the red part is the right table reading, the blue part is the left table reading. The results is shown in table 10.

Table 10 The results of temperature shrinkage coefficient test

\begin{tabular}{cccccccc}
\hline Trial part number & AZ & BC1 & BC2 & BW1 & BW2 & BS1 & BS2 \\
\hline Temperature shrinkage coefficient $\left(10^{-6} /{ }^{\circ} \mathrm{C}\right)$ & 3.52 & 3.04 & 4.34 & 3.92 & 2.45 & 5.26 & 2.87 \\
\hline
\end{tabular}

The temperature shrinkage coefficient of semi rigid material is $10 \times 10^{-6} /{ }^{\circ} \mathrm{C}$ and Table 10 shows that the temperature shrinkage coefficient of RCCis significantly smaller, and the average value can be taken as $4 \times 10^{-6} \%{ }^{\circ} \mathrm{C}$.

From the experimental results, it can be seen that the temperature shrinkage coefficient of RCC is increasing with the increase of cement dosage, water consumption, or sand percentage. Therefore, in order to reduce the temperature and shrinkage deformation of RCC, selecting the smaller water 
content, controlling the cement dosage and sand ratio in designing the mix of roller compacted concrete when it can meet the requirements of bending tensile strength and workability.

In the upper section, the temperature shrinkage coefficient of material reduced $1 \times 10^{-6} /{ }^{\circ} \mathrm{C}$, and the temperture stress ireduced 0.06 MPa. Therefore, when the temperature shrinkage coefficient of RCC is taken as $4 \times 10^{-6} /{ }^{\circ} \mathrm{C}$, compared with the traditional semi-rigid base, the temperature stress decreases $0.36 \mathrm{Mpa}$, the decrease amplitude of temperature stress is $40 \%$, the ability to resist cracking is better.

Combined with the changing rule of temperture stress of RCC and the temperature shrinkage performance, it can realize the durability of roller compacted concrete base of asphalt pavement by reasonable size of the slab, increasing the thickness of the asphalt layer and RCC slab and improving the design of mix proportion.

\section{Conclusions}

This study focussed on developing the temperature stress distribution of roller compacted concrete $(\mathrm{RCC})$ base by conducting appropriate experiments and developing a simplified theoretical model in the case of the transient loading situation.To demonstrate the effect of the length, width, thickness of roller compacted concrete plate, temperature shrinkage coefficient, modulus, temperature gradient and the thickness of asphalt layer, a series of three-dimensional finite element simulations were conducted.To demonstrate the temperature shrinkage performance of RCC, a large number of laboratory tests were conducted.

The results indicated that changing the variables of RCC influenced the temperature stress distribution in laboratory specimens. Increasing the width, thickness of roller compacted concrete plate and decreasing the length, temperature shrinkage coefficient, modulus, temperature gradient and the thickness of asphalt layer can assited in reducing the temperature stress. In addition, laboratory tests showed that compared with the traditional semi-rigid base, the temperature shrinkage coefficient of $\mathrm{RCC}$ is less, the cracking resistance of RCC is better, and the decrease amplitude of temperature stress is $40 \%$. It can realize the durability of RCC base of asphalt pavement by reasonable construction technology and structure design.

\section{Acknowledgements}

This work was financially supported by science and technology projects of Guangdong province transportation hall (2010-02-006)

\section{References}

[1] JTG D40 -2002 .Specifications of cement concrete pavement design for highway [ S] . Bei jing :China Communications Press, 2003

[2] ZHENG Mulian, WANG Songgen, CHEN Shuanfa, et al.Load stress numerical calculation for concrete base of durable asphalt pavement[ J] .China Journal of Highway and Tr ansport , 2008 , 21(2):28 .

[3] Research on key technology of roller compacted concrete base [R]. Guangzhou: Guangdong province grow up Highway Engineering Co., LTD, 2008

[4] HU Changshun, WANG Bingg ang. Design principle and construction technology for compound pavement[ M] .Bei jing :China Communications Press, 1999 .

[5] Shen Jinan. Application of the Roller Compacted Concrete (RCC)in Freeways of Japan [J]. Journal of Highway and Transportation Research and Development, 1991 (4): 63-72

[6] Li Shiqi. High grade highway roller compacted concrete pavement technology [J]. Journal of Highway andTransportation Reseach andk Development, 1997 (1): 29-33 
[7] Chen Yan. Application of Rolled Concrete Substratum in Expanding Project of Beijing - Zhuhai Expressway [J]. Technology of Highway and Transport, 2007 (3):13-17. 